\title{
Anterior Shoulder Instability
}

\section{A Systematic Review of the Quality and Quantity of the Current Literature for Surgical Treatment}

\author{
Haley Glazebrook, ${ }^{, \dagger}$ BSc, Blair Miller,${ }^{\ddagger}$ and Ivan Wong, ${ }^{\ddagger}$ MD, FRCS(C), DipSportsMed, MACM \\ Investigation performed at the Division of Orthopedic Surgery, Dalhousie University, \\ and Queen Elizabeth II Health Sciences Center, Halifax Infirmary, Halifax, Nova Scotia, Canada
}

\begin{abstract}
Background: Anterior shoulder instability is the most common sequela of shoulder dislocation and can result in repeated dislocations or subluxation of the glenohumeral joint. Anterior shoulder instability can be treated conservatively or surgically with several procedures.
\end{abstract}

Purpose: To date, arthroscopic Bankart is the most common surgical procedure for the treatment of anterior shoulder instability. No previous studies have compared all anterior shoulder surgical procedures. In this study, the authors performed a systematic review of journal articles describing all surgical procedures for anterior shoulder instability to determine the scientific evidence and level of recommendation.

Study Design: Systematic review; Level of evidence, 4.

Method: A comprehensive literature search was conducted (July 19, 2016) with 4 reputed databases: PubMed, EMBASE, the Cochrane databases, and Web of Science. The articles found in the literature search were screened by 2 reviewers on the basis of their titles, abstracts, and full text. Data were extracted from relevant studies, and potentially relevant records were selected for fulltext review. Included articles were classified according to their scientific quality (level of evidence, 1-5). The studies were then combined for each surgical procedure, and a grade of recommendation was assigned for each procedure: grade $A$, treatment recommendation based on level 1 evidence studies; B, based on level 2 or 3 evidence studies; C, based on level 4 or 5 evidence and could represent conflicting results; or I, insufficient evidence to recommend a treatment. As such, the grade of recommendation provides a summary score for the quality and quantity of available literature to support the surgical procedures reviewed here.

Results: The systematic literature review generated 11,281 articles. After screening, 655 articles were included. Results revealed 31 surgical procedures for shoulder instability following dislocation: 10 surgical procedures were given an $\mathrm{A}$ or $\mathrm{B}$ recommendation; 11, a C recommendation; and 10, an I recommendation.

Conclusion: This review identified many surgical procedures to treat anterior shoulder instability. Ten of these surgical procedures had an abundant amount of published articles to describe their safety and efficacy. Arthroscopic Bankart and open Bankart were the most commonly reported procedures that cite satisfactory postoperative outcomes and limited complications. Publications on the other surgical procedures were less common. Surgeons should be careful when recommending surgery, and they should choose the appropriate surgical procedure based on evidence-based literature.

Keywords: shoulder; glenohumeral; instability; dislocation; surgery

Anterior shoulder instability occurs when the humerus translates anterior to the glenoid, and it is the most common form of shoulder instability. Shoulder instability can occur for a variety of reasons, and over the years, different procedures and techniques have been developed with respect to specific indications. The number of pathologic conditions in the glenohumeral joint include joint laxity, labral tears, and ligament injuries, as well as bone defects in the humeral head (Hill-Sachs lesion) and/or the glenoid.

The Orthopaedic Journal of Sports Medicine, 6(11), 2325967118805983 DOI: $10.1177 / 2325967118805983$

(c) The Author(s) 2018
Anterior shoulder instability can be treated either nonoperatively or operatively by numerous procedures, such as open Bankart, ${ }^{16,17}$ arthroscopic Bankart, ${ }^{4,10}$ Latarjet, ${ }^{1,3}$ Bristow, ${ }^{76,77}$ and older techniques, such as Putti-Platt ${ }^{72,74}$ and Magnuson-Stack. ${ }^{2,24}$ Arthroscopic and open Bankart procedures are performed on patients with glenoid labral tears. The indication for the Latarjet procedure is glenoid bone loss. The coracoid process is cut and transferred with the conjoined tendon through a horizontal incision in the subscapularis tendon. Bristow surgery is similar to that of the Latarjet; however, just the coracoid process is transferred to the glenoid with its muscle attachments. The Putti-Platt and Magnuson-Stack procedures are

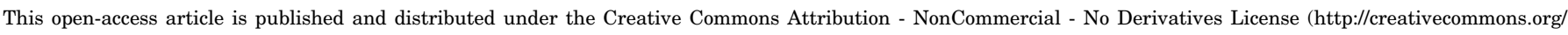

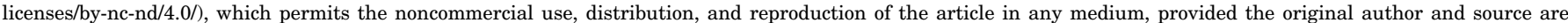

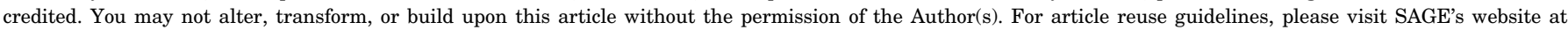
http://www.sagepub.com/journals-permissions. 


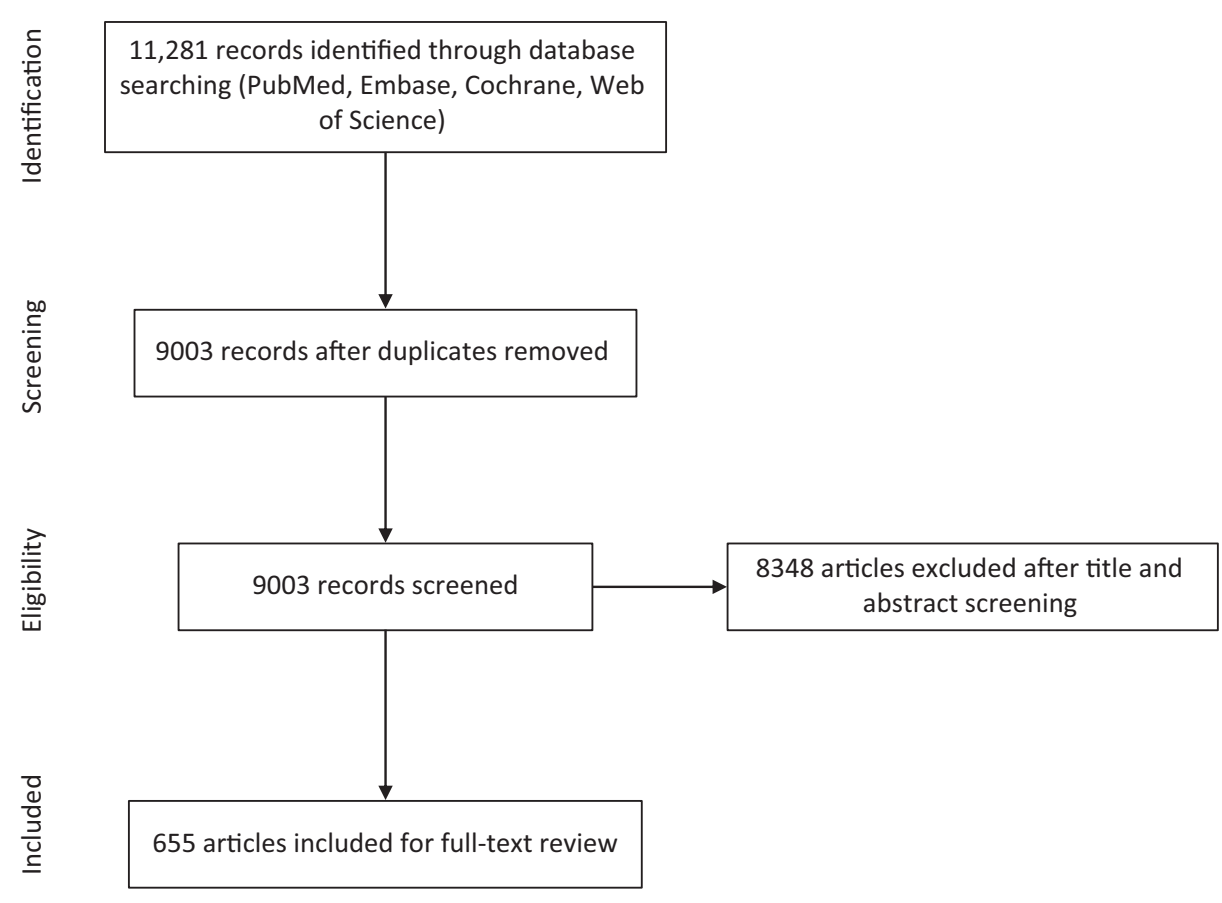

Figure 1. PRISMA (Preferred Reporting Items for Systematic Meta-Analyses) flow diagram: the search process for published literature from the online databases that met the inclusion criteria for this study.

nonanatomic historical procedures that involve tightening of the subscapularis tendon.

In recent years, many of these surgical procedures have been performed arthroscopically and have shown promising results. ${ }^{7}$ Systematic reviews comparing operative and nonoperative treatment and certain surgical procedures have been published, ${ }^{44}$ but never has a systematic review evaluated all surgical procedures for anterior shoulder dislocation. The aim of this systematic review was to determine the quantity and quality of the available scientific evidence supporting all surgical procedures for anterior shoulder dislocations.

\section{METHODS}

A comprehensive literature search was performed of the following databases from their inception dates to July 19, 2016: PubMed, EMBASE, Cochrane databases, and Web of Science. The search strategy developed for PubMed, which was modified for other databases, was as follows: the search terms [Shoulder (MeSH) OR Glenohumeral] AND [Dislocation OR Shoulder Dislocation] AND [Anterior] AND [Surg* (MeSH) OR Operation (MeSH) OR Orthopedic] with filters: English. The search terms included 3 concepts: anterior shoulder dislocations, glenohumeral joint, and surgical procedures. All published clinical studies with English translation were included. This systematic review excluded non-English studies, cadaveric studies, biomechanical studies, nonhuman studies, review articles, shoulder instability studies (without dislocation), and posterior and inferior shoulder dislocation studies.

The methods for the comprehensive review of the literature are found in the PRISMA (Preferred Reporting Items for Systematic Meta-Analyses) flow diagram (Figure 1). All records found in the literature search were screened by titles and abstracts. Articles were considered relevant and selected for full-text review if they did not include any of the exclusion criteria. Articles were then classified into levels 1 to 5 according to their quality of evidence (ie, research method) per the criteria of Wright et al. ${ }^{87}$ If the level of evidence for the article was assigned by its publication journal, then that was used. If the level of evidence was not preassigned by the author or the journal, the methods of Wright et $\mathrm{al}^{87}$ were used to assign a level of evidence, as agreed on by all authors of this review. Articles that described case series with $<5$ patients, had poor quality data collection, or were written on only the basis of expert opinion were classified as level 5 evidence. Randomized controlled trials were considered the highest-quality studies and were classified as level 1.

\footnotetext{
*Address correspondence to Haley Glazebrook, BSc, Queen Elizabeth II Health Sciences Center, Halifax Infirmary (Room 4867), 1796 Summer Street, Halifax, Nova Scotia, B3 H 3A7, Canada (email: haleyglazebr@hotmail.com).

${ }^{\dagger}$ Faculty of Science, Dalhousie University, Halifax, Nova Scotia, Canada.

${ }^{\ddagger}$ Dalhousie University, Halifax, Nova Scotia, Canada.

The authors declared that they have no conflicts of interest in the authorship and publication of this contribution. AOSSM checks author disclosures against the Open Payments Database (OPD). AOSSM has not conducted an independent investigation on the OPD and disclaims any liability or responsibility relating thereto.
} 
TABLE 1

Quality and Quantity of the Current Literature on Anterior Shoulder Instability

\begin{tabular}{|c|c|c|c|c|c|c|c|}
\hline \multirow[b]{2}{*}{ Surgery Type } & \multicolumn{5}{|c|}{ Level of Evidence, No. of Studies } & \multirow[b]{2}{*}{$\mathrm{GOR}^{a}$} & \multirow[b]{2}{*}{ Recommendation } \\
\hline & 1 & 2 & 3 & 4 & 5 & & \\
\hline Arthroscopic Bankart ${ }^{b}$ & 19 & 35 & 23 & 173 & 9 & $\mathrm{~A}$ & For \\
\hline Open Bankart ${ }^{c}$ & 13 & 21 & 23 & 55 & 2 & A & For \\
\hline Lartarjet $^{1,3,12}$ & 1 & 6 & 9 & 72 & 8 & $\mathrm{~A}$ & For \\
\hline Putti-Platt ${ }^{72,74,88}$ & 1 & 2 & 7 & 24 & & $\mathrm{~A}$ & Against \\
\hline Arthroscopic remplissage ${ }^{53,59}$ & & 2 & & 7 & 1 & $\mathrm{~B}$ & For \\
\hline Remplissage $^{42}$ & & 1 & 1 & 4 & 1 & $\mathrm{~B}$ & For \\
\hline Arthroscopic lavage ${ }^{82-85}$ & 2 & 2 & & & & $\mathrm{~B}$ & For \\
\hline Bristow $^{76,77,89}$ & & 1 & 2 & 16 & 3 & $\mathrm{~B}$ & Against \\
\hline Open capsular shift ${ }^{47,58}$ & 1 & 3 & 3 & 14 & & $\mathrm{~B}$ & Against \\
\hline Thermal capsulorrhaphy ${ }^{15,28,35,36,46}$ & 2 & 4 & 4 & 22 & 4 & $\mathrm{~B}$ & Inconclusive data \\
\hline Arthroscopic Latarjet ${ }^{13,14,25,26,32}$ & & & 1 & 7 & 2 & $\mathrm{C}$ & For \\
\hline Open J graft ${ }^{66,67}$ & & & 1 & 5 & 1 & $\mathrm{C}$ & For \\
\hline Latarjet-Patte 68 & & & & 3 & 1 & $\mathrm{C}$ & For \\
\hline Iliac crest bone graft ${ }^{65,78}$ & & & & 7 & & $\mathrm{C}$ & For \\
\hline Magnuson-Stack ${ }^{2,24,52}$ & & & 3 & 9 & & $\mathrm{C}$ & Against \\
\hline Bankart and remplissage $\mathrm{e}^{40,70}$ & & 1 & 1 & 2 & & $\mathrm{C}$ & Against \\
\hline Eden-Hybbinette ${ }^{23,30,43}$ & & & 4 & 12 & & $\mathrm{C}$ & Against \\
\hline Boytchev 45,79 & & & 1 & 10 & & $\mathrm{C}$ & Against \\
\hline Arthroscopic staple capsulorrhaphy ${ }^{50}$ & & & 1 & 6 & & $\mathrm{C}$ & Against \\
\hline Stapling operation ${ }^{31,38}$ & & & & 7 & & $\mathrm{C}$ & Against \\
\hline Caspari technique $^{51}$ & & 1 & & 5 & & $\mathrm{C}$ & Against \\
\hline Bankart and Bristow $^{5}$ & & & & 3 & & I & \\
\hline Weber derotation osteotomy ${ }^{22}$ & & & & 2 & & I & \\
\hline Arthroscopic Bristow-Latarjet-Bankart ${ }^{19}$ & & & 1 & 2 & & I & \\
\hline Bankart and capsulorrhaphy ${ }^{61}$ & & & & 2 & & I & \\
\hline Neer T-plasty with Bankart 69 & & 1 & & 1 & & I & \\
\hline Nicola operation 57,81 & & & & 2 & 1 & I & \\
\hline M. Lange ${ }^{60}$ & & & 1 & 4 & & I & \\
\hline Bankart-Delitala ${ }^{56}$ & & & & 2 & & I & \\
\hline Arthroscopic capsuloplasty ${ }^{73,75}$ & & & & 3 & & I & \\
\hline Spaso technique ${ }^{90,91}$ & & & & 1 & 1 & I & \\
\hline
\end{tabular}

${ }^{a} \mathrm{GOR}$, grade of recommendation per Wright et al. ${ }^{86}$

${ }^{b}$ References 4, 6-10, 20, 21, 26, 37, 41, 44, 48, 49, 54, 55, 62-64, 71, 80.

${ }^{c}$ References 11, 16-18, 27, 29, 33, 34, 39, 49, 54, 62, 63, 71.

After assignment of quality of evidence (levels 1-5), articles were grouped and analyzed according to surgical procedure. Each surgical procedure was given a grade of recommendation (A, B, C, or I) for or against the procedure, according to Wright et al. ${ }^{86}$ Grade A recommendations are based on consistent level 1 studies, while grade B recommendations consist of level 2 or 3 evidence studies. Grade $\mathrm{C}$ recommendations are based on level 4 or 5 evidence and could represent conflicting results. Grade I articles have insufficient evidence to recommend a treatment. As such, the grade of recommendation provides a summary score of the quality and quantity of available literature to support the surgical procedures reviewed here.

\section{RESULTS}

The comprehensive literature searches of the 4 electronic databases generated 11,281 articles. After duplicates were removed and articles were screened by title, abstract, and full-text review, 655 articles met the inclusion criteria, generating 31 surgical procedures for anterior shoulder dislocations (Table 1).

Four surgical procedures were given a grade A recommendation. Arthroscopic Bankart, open Bankart, and Latarjet were all given a grade $\mathrm{A}$ in favor of recommendation, whereas the Putti-Platt procedure was given a grade A against recommendation. There were 259 articles on arthroscopic Bankart, including 19 level 1 studies $^{\S}$ describing several merits, such as lower rates of recurrent instability, fewer postoperative complications, and increased range of motion and strength, as well as an increased outcome score. There were 114 articles on open Bankart, including 13 level 1 studies."

Six surgical procedures were given a grade B recommendation. Ten articles were included for arthroscopic

\footnotetext{
§References 4, 6-10, 20, 21, 26, 37, 41, 48, 64.

"References 11, 16-18, 27, 29, 33, 34, 39, 49, 54, 62, 63, 71.
} 
remplissage, 7 for remplissage, and 4 for arthroscopic lavage. These 3 procedures were given a grade B in favor of recommendation and were supported by the literature. Bristow and open capsular shift surgical procedures were given a grade $\mathrm{B}$ against recommendation. There were 36 articles on thermal capsulorrhaphy, and it was determined to have conflicting recommendations.

Of the 11 grade $\mathrm{C}$ surgical procedures, 7 were given a grade $\mathrm{C}$ against recommendation: Magnuson-Stack, Bankart and remplissage, Boytchev, Eden-Hybbinette, arthroscopic staple capsulorrhaphy, stapling operation, and Caspari technique. The 4 surgical procedures given a grade $\mathrm{C}$ in favor of recommendation were open $\mathrm{J}$ graft, arthroscopic Latarjet, Latarjet-Patte, and iliac crest bone graft.

Of the 31 surgical procedures, 10 were given an I recommendation because of insufficient evidence (Table 1).

\section{DISCUSSION}

Of the 4 surgical procedures that were graded A, PuttiPlatt was not recommended. Few articles provided adequate support for using this surgical procedure, as it is an old procedure and the published literature is out of date. Furthermore, the redislocation rate is very high for the Putti-Platt surgical procedure, and range of motion is compromised. ${ }^{72,74,88}$ Based on the findings, the Putti-Platt procedure is not recommended as a treatment option for anterior shoulder instability. There was abundance of literature on arthroscopic and open Bankart repair. Systematic reviews and meta-analysis mentioned that open Bankart was superior to arthroscopic Bankart, with a lower recurrence rate and no significant difference in complication rate. ${ }^{6,41}$ Some level 1 randomized controlled trials comparing arthroscopic Bankart and open Bankart showed comparable postoperative results in terms of stability, range of motion, and complications. ${ }^{20,37}$ However, other level 1 studies suggested that both surgical procedures are adequate, with arthroscopic Bankart offering better postoperative results, such as greater stability, fewer complications, and better range of motion. ${ }^{55}$ The Latarjet procedure was reported to have promising results, including lower recurrence rates, high graft union, satisfactory outcome scores, and fewer complications. ${ }^{1,3,12}$

Of the procedures that were graded B in favor of recommendation, arthroscopic remplissage was reported by several studies to have no restriction of movements, improved outcome scores, fewer complications, and early return to sports activities. ${ }^{53,59}$ The remplissage procedure also showed a high stability rate, increased range of motion, and early return to sports activities. ${ }^{42}$ Several randomized and nonrandomized studies reported beneficial results of arthroscopic lavage, including a lower recurrence rate, a higher stability rate, improved outcome scores, and reduced effusion in the glenohumeral joint, ${ }^{82-85}$ ultimately leading to higher patient satisfaction.

There were 2 procedures that were graded B against recommendation: the Bristow procedure and open capsular shift. Bristow is a relatively old technique, with advantages such as improved range of motion and being a safe surgical technique. However, this technique also has a number of complications, including recurrent painful anterior instability, injury to the articular cartilage, loosening of the screw, neurovascular injury, and posterior instability. $^{76,77,89}$ Open capsular shift is an uncommon surgical procedure reported to have complications such as synovial and vascular reaction of the glenohumeral joint. ${ }^{47,58} \mathrm{As}$ such, it is not surprising that the findings of this review revealed mainly level 2 or 3 studies with consistent findings against recommending Bristow and open capsular shift.

Thermal capsulorrhaphy was deemed conflicting; as such, more high-quality studies are necessary in this area. Few articles showed complications when thermal capsulorrhaphy ${ }^{28}$ was performed on its own, such as recurrence, stiffness, axillary nerve injuries, ${ }^{15}$ high unsatisfactory rate of pain, recurrent instability, return to work/ sports, and outcome scores. However, some studies suggested that thermal capsulorrhaphy enhances outcomes when performed with other surgical procedures, such as arthroscopic Bankart. ${ }^{46}$

Of the procedures that were graded $\mathrm{C}$ in favor of recommendation, arthroscopic Latarjet has been practiced by surgeons for the treatment of anterior shoulder instability with satisfactory outcome scores and stability rate as well as few complications, such as apprehension and dislocation. ${ }^{13,14,25,26,32}$ Open $\mathrm{J}$ bone graft was also indicated for the reconstruction of glenoid bone, which had satisfactory graft positioning and bone remodeling; however, it is not practiced widely. ${ }^{66,67}$ The Latarjet-Patte procedure was used on rugby players in 1 study and demonstrated excellent outcomes regarding stability and early successful return to rugby playing. ${ }^{68}$ One study showed that glenoid reconstruction with iliac crest autograft had positive results in terms of stabilization and outcome score, ${ }^{78}$ while 1 study mentioned graft osteolysis and an unsatisfactory clinical outcome. ${ }^{65}$

Seven procedures were graded $\mathrm{C}$ against recommendation: Magnuson-Stack, ${ }^{2,24,52}$ Bankart and remplissage, ${ }^{40,70}$ Eden-Hybbinette, ${ }^{23,30,43}$ Boytchev, ${ }^{45,79}$ arthroscopic staple capsulorrhaphy, ${ }^{50}$ stapling operation, ${ }^{31,38}$ and Caspari technique. $^{51}$ These techniques are not commonly used and are reported to have adverse postoperative findings, such as redislocation, reduced range of motion, and infections. Moreover, there was not a sufficient number of articles available to convince us to recommend these procedures as a suitable treatment option for anterior shoulder instability.

The limitations of this study include the lack of ability to access all articles on each surgical procedure, as a number of surgical procedures that are not used anymore have few quality studies published. It is possible that publications exist but were never transferred to web databases and thus cannot be found. It is also possible that the information in these articles is out of date. Some surgical procedures that received an I recommendation are new techniques and surgical procedures that require further research before being supported by the literature. The large scope of the study and the broadness of the topic make it difficult to draw specific conclusions. If this study were to be repeated, the topic should be focused on a narrower research question. 
Another limitation stems from the number of pathologic conditions in the glenohumeral joint, such as joint laxity, labral tears, ligament injuries, as well as bone defects in the humeral head (Hill-Sachs lesion) and/or the glenoid. As such, the various surgical procedures reviewed in this study may be more tailored for one pathologic identity of shoulder instability than another. Thus, per our conclusion, we recommended not only taking into account the quality and quantity of evidence reviewed here but also considering the pathology involved in the patient's instability.

\section{CONCLUSION}

A comprehensive review provided abundant literature on anterior shoulder dislocation, with ample studies ranging from level 1 to level 5. It is evident that the arthroscopic and open Bankart procedures have been heavily studied and are well supported by the literature. Future research should focus on various aspects of the Bankart procedure to optimize results, such as suture type, suture location, rehabilitation, and so on. With the quantity and quality of the literature to support several surgical procedures for the treatment of anterior shoulder dislocations, surgeons should ensure that their procedure of choice is supported by the literature and are appropriate for each patient's needs and the specific indications that each procedure provides. In summary, this study provides a single comprehensive source of the available literature on the surgical procedures for anterior shoulder instability.

\section{REFERENCES}

1. Abdelhady A, Abouelsoud M, Eid M. Latarjet procedure in patients with multiple recurrent anterior shoulder dislocation and generalized ligamentous laxity. Eur J Orthop Surg Traumatol. 2015;25(4):705-708.

2. Ahmadain AM. The Magnuson-Stack operation for recurrent anterior dislocation of the shoulder: a review of 38 cases. J Bone Joint Surg Br. 1987;69(1):111-114.

3. Allain J, Goutallier D, Glorion C. Long-term results of the Latarjet procedure for the treatment of anterior instability of the shoulder. J Bone Joint Surg Am. 1998;80(6):841-852.

4. Altchek DW. Arthroscopic shoulder stabilization using a bioabsorbable fixation device. Instr Course Lect. 1996;45:91-96.

5. Amako M, Imai T, Okamura K. Recovery of shoulder rotational muscle strength after a combined Bankart and modified Bristow procedure. J Shoulder Elbow Surg. 2008;17(5):738-743.

6. An VVG, Sivakumar BS, Phan K, Trantalis J. A systematic review and meta-analysis of clinical and patient-reported outcomes following two procedures for recurrent traumatic anterior instability of the shoulder: Latarjet procedure vs Bankart repair. J Shoulder Elbow Surg. 2016; 25(5):853-863.

7. Antunes JP, Mendes A, Prado MH, Moro OP, Miró RL. Arthroscopic Bankart repair for recurrent shoulder instability: a retrospective study of 86 cases. J Orthop. 2016;13(2):95-99.

8. Arciero RA, Taylor DC, Snyder RJ, Uhorchak JM. Arthroscopic bioabsorbable tack stabilization of initial anterior shoulder dislocations: a preliminary report. Arthroscopy. 1995;11(4):410-417.

9. Arciero RA, Wheeler JH, Ryan JB, McBride JT. Arthroscopic Bankart repair versus nonoperative treatment for acute, initial anterior shoulder dislocations. Am J Sports Med. 1994;22(5):589-594.

10. Armangil M, Basat HÇ, Akan B, Karaduman M, Demirtaş M. Arthroscopic stabilization of anterior shoulder instability using a single anterior portal. Acta Orthop Traumatol Turc. 2015;49(1):6-12.
11. Arzi H, Krasovsky T, Pritsch M, Liebermann DG. Movement control in patients with shoulder instability: a comparison between patients after open surgery and nonoperated patients. J Shoulder Elbow Surg. 2014;23(7):982-992.

12. Atalar AC. Modified Latarjet procedure for patients with glenoid bone defect accompanied with anterior shoulder instability. Acta Orthop Traumatol Turc. 2013;47(6):393-399.

13. Athwal GS, Meislin R, Getz C, Weinstein D, Favorito P. Short-term complications of the arthroscopic Latarjet procedure: a North American experience. Arthroscopy. 2016;32(10):1965-1970.

14. Aurich M, Hofmann GO, Gras F. Reconstruction of the coracoacromial ligament during a modified Latarjet procedure: a case series. BMC Musculoskelet Disord. 2015;16(1):238.

15. Barber FA, Uribe JW, Weber SC. Current applications for arthroscopic thermal surgery. Arthroscopy. 2002;18(2 suppl 1):40-50.

16. Berendes TD, Wolterbeek R, Pilot $P$, Verburg H, te Slaa RL. The open modified Bankart procedure: outcome at follow-up of 10 to 15 years. J Bone Joint Surg Br. 2007;89(8):1064-1068.

17. Berg EE, Ellison AE. The inside-out Bankart procedure. Am J Sports Med. 1990;18(2):129-133.

18. Boileau P, Fourati E, Bicknell R. Neer modification of open Bankart procedure: what are the rates of recurrent instability, functional outcome, and arthritis? Clin Orthop Relat Res. 2012;470(9): 2554-2560.

19. Boileau P, Mercier N, Roussanne Y, Thélu C-É, Old J. Arthroscopic Bankart-Bristow-Latarjet procedure: the development and early results of a safe and reproducible technique. Arthroscopy. 2010; 26(11):1434-1450.

20. Bottoni CR, Smith EL, Berkowitz MJ, Towle RB, Moore JH. Arthroscopic versus open shoulder stabilization for recurrent anterior instability. Am J Sports Med. 2006;34(11):1730-1737.

21. Bottoni CR, Wilckens JH, DeBerardino TM, et al. A prospective, randomized evaluation of arthroscopic stabilization versus nonoperative treatment in patients with acute, traumatic, first-time shoulder dislocations. Am J Sports Med. 2002;30(4):576-580.

22. Brooks-Hill AL, Forster BB, van Wyngaarden C, Hawkins R, Regan WD. Weber osteotomy for large Hill-Sachs defects: clinical and CT assessments. Clin Orthop Relat Res. 2013;471(8):2548-2555.

23. Brox JI, Finnanger AM, Merckoll E, Lereim P. Satisfactory long-term results after Eden-Hybbinette-Alvik operation for recurrent anterior dislocation of the shoulder: 6-20 years' follow-up of 52 patients. Acta Orthop Scand. 2003;74(2):180-185.

24. Bryan RS, DiMichele JD, Ford GL, Cary GR. Anterior recurrent dislocation of the shoulder: report of a series of the Augustine variation of Magnuson-Stack repair. Clin Orthop Relat Res. 1969;63:177-180.

25. Casabianca L, Gerometta A, Massein A, et al. Graft position and fusion rate following arthroscopic Latarjet. Knee Surg Sports Traumatol Arthrosc. 2016;24(2):507-512.

26. Castagna A, Borroni M, Delle Rose G, et al. Effects of posteriorinferior capsular plications in range of motion in arthroscopic anterior Bankart repair: a prospective randomized clinical study. Knee Surg Sports Traumatol Arthrosc. 2009;17(2):188-194.

27. Cetik O, Uslu M, Ozsar BK, Eksioglu F, Cetik G. Open repair of Bankart lesions using suture anchors in hard workers. Acta Orthop Belg. 2006;72(6):664-670.

28. D'Alessandro DF, Bradley JP, Fleischli JE, Connor PM. Prospective evaluation of thermal capsulorrhaphy for shoulder instability: indications and results, two- to five-year follow-up. Am J Sports Med. 2004; 32(1):21-33.

29. Dahabra IA. Open Bankart repair using suture anchors and capsular shift for recurrent anterior shoulder dislocation. Saudi Med J. 2005; 26(6):1020-1022.

30. De Nicola U, Bosch HC. Cancellous metal implant in the surgical treatment of recurrent post-traumatic shoulder dislocation [in German]. Z Orthop Ihre Grenzgeb. 2008;131(4):323-328.

31. du Toit GT, Roux D. Recurrent dislocation of the shoulder: a twentyfour year study of the Johannesburg stapling operation. $J$ Bone Joint Surg Am. 1956;38(1):1-12. 
32. Dumont GD, Fogerty S, Rosso C, Lafosse L. The arthroscopic latarjet procedure for anterior shoulder instability: 5-year minimum follow-up. Am J Sports Med. 2014;42(11):2560-2566.

33. Ejerhed L, Kartus J, Funck E, Köhler K, Sernert N, Karlsson J. Absorbable implants for open shoulder stabilization: a clinical and serial radiographic evaluation. J Shoulder Elbow Surg. 2000;9(2):93-98.

34. Ejerhed L, Kartus J, Funck E, Köhler K, Sernert N, Karlsson J. A clinical and radiographic comparison of absorbable and nonabsorbable suture anchors in open shoulder stabilisation. Knee Surg Sports Traumatol Arthrosc. 2000;8(6):349-355.

35. Enad JG, EIAttrache NS, Tibone JE, Yocum LA. Isolated electrothermal capsulorrhaphy in overhand athletes. J Shoulder Elbow Surg. 2004;13(2):133-137.

36. Enad JG, Kharrazi FD, EIAttrache NS, Yocum LA. Electrothermal capsulorrhaphy in glenohumeral instability without Bankart tear. Arthroscopy. 2003;19(7):740-745.

37. Fabbriciani C, Milano G, Demontis A, Fadda S, Ziranu F, Mulas PD. Arthroscopic versus open treatment of Bankart lesion of the shoulder: a prospective randomized study. Arthroscopy. 2004;20(5):456-462.

38. Fantasia L, Mollica G, Pavarini M. Recurrent anterior dislocation of the shoulder: stabilising procedure with staple. J Orthop Traumatol. 2002; 3(3):171-175.

39. Farooq $\mathrm{O}$, Hafeez $\mathrm{S}$. Modified suture anchors for open bankart repair. J Coll Physicians Surg Pak. 2012;22(1):23-26.

40. Franceschi F, Papalia R, Rizzello G, et al. Remplissage repair-new frontiers in the prevention of recurrent shoulder instability: a 2-year follow-up comparative study. Am J Sports Med. 2012;40(11): 2462-2469.

41. Freedman KB, Smith AP, Romeo AA, Cole BJ, Bach BR. Open Bankart repair versus arthroscopic repair with transglenoid sutures or bioabsorbable tacks for recurrent anterior instability of the shoulder. Am J Sports Med. 2004;32(6):1520-1527.

42. Garcia GH, Wu H-H, Liu JN, Huffman GR, Kelly JD. Outcomes of the remplissage procedure and its effects on return to sports: average 5year follow-up. Am J Sports Med. 2016;44(5):1124-1130.

43. Gebhard F, Draeger M, Steinmann R, Hoellen I, Hartel W. Posttraumatic recurrent shoulder dislocation and the modified Eden-Hybinette procedure-results from the viewpoint of function. Unfallchirurg. 1997;100(10):770-775.

44. Godin J, Sekiya JK. Systematic review of arthroscopic versus open repair for recurrent anterior shoulder dislocations. Sports Health. 2011;3(4):396-404.

45. Ha'Eri GB. Boytchev procedure for the treatment of anterior shoulder instability. Clin Orthop Relat Res. 1986;(206):196-201.

46. Hawkins RJ, Karas SG. Arthroscopic stabilization plus thermal capsulorrhaphy for anterior instability with and without Bankart lesions: the role of rehabilitation and immobilization. Instr Course Lect. 2001; 50:13-15.

47. Hayashi K, Massa KL, Thabit G, et al. Histologic evaluation of the glenohumeral joint capsule after the laser-assisted capsular shift procedure for glenohumeral instability. Am J Sports Med. 1999;27(2): 162-167.

48. Hiemstra LA, Sasyniuk TM, Mohtadi NGH, Fick GH. Shoulder strength after open versus arthroscopic stabilization. Am J Sports Med. 2008; 36(5):861-867.

49. Hobby J, Griffin D, Dunbar M, Boileau P. Is arthroscopic surgery for stabilisation of chronic shoulder instability as effective as open surgery? A systematic review and meta-analysis of 62 studies including 3044 arthroscopic operations. J Bone Joint Surg Br. 2007;89(9): 1188-1196.

50. Hodgkinson JP, Case DB. The modified staple capsulorrhaphy for the correction of recurrent anterior dislocation of the shoulder. Injury. 1987;18(1):51-54.

51. Kagaya K, Yoneda M, Hayashida K, et al. Modified Caspari technique for traumatic anterior shoulder instability: comparison of absorbable sutures versus absorbable plus nonabsorbable sutures. Arthroscopy. 1999;15(4):400-407.

52. Karadimas JE. Recurrent traumatic anterior dislocation of the shoulder: 218 consecutive cases treated by a modified Magnuson-Stack procedure and follow for 2-18 years. Acta Orthop Scand Suppl. 1997; 275:69-71.

53. Ko S-H, Shin S-M, Jo B-G. Outcomes of minimally 1 year follow-up for the arthroscopic remplissage technique with Hill-Sachs lesion. J Orthop. 2013;10(1):41-45.

54. Lenters TR, Franta AK, Wolf FM, Leopold SS, Matsen FA. Arthroscopic compared with open repairs for recurrent anterior shoulder instability: a systematic review and meta-analysis of the literature. J Bone Joint Surg Am. 2007;89(2):244.

55. Lützner J, Krummenauer F, Lübke J, Kirschner S, Günther K-P, Bottesi M. Fuctional outcome after open and arthroscopic Bankart repair for traumatic shoulder instability. Eur J Med Res. 2009;14(1):18-24.

56. Maiotti M, Ingravalle R, Reali G, De Pedis M. Bankart-Delitala surgery in the treatment of recurrent anterior dislocation of the shoulder. Chir Organi Mov. 1997;82(1):53-59.

57. Mangels M, Robinson CA. Modified Nicola operation for correction of recurring anterior dislocations of the shoulder. South Med J. 1947; 40(9):784-786.

58. Marquardt B, Pötzl W, Witt K-A, Steinbeck J. A modified capsular shift for atraumatic anterior-inferior shoulder instability. Am J Sports Med. 2005;33(7):1011-1015.

59. McCabe MP, Weinberg D, Field LD, O’Brien MJ, Hobgood ER, Savoie $\mathrm{FH}$. Primary versus revision arthroscopic reconstruction with remplissage for shoulder instability with moderate bone loss. Arthroscopy. 2014;30(4):444-450.

60. Melzer C, Manz P, Krödel A, Stürz H. Operative therapy for recurrent shoulder dislocation with special regard to long-term clinical and radiological results using M. Lange technique. Arch Orthop Trauma Surg. 1989;108(2):107-111.

61. Mochón Halabe C, Torton SA. Treatment of anterior shoulder instability: arthroscopic thermal capsulorraphy and Bankart technique [in Spanish]. Acta Ortop Mex. 2008;22(5):303-308.

62. Mohtadi NG, Chan DS, Hollinshead RM, et al. A randomized clinical trial comparing open and arthroscopic stabilization for recurrent traumatic anterior shoulder instability. J Bone Joint Surg Am. 2014;96(5): 353-360.

63. Mohtadi NGH, Bitar IJ, Sasyniuk TM, Hollinshead RM, Harper WP. Arthroscopic versus open repair for traumatic anterior shoulder instability: a meta-analysis. Arthroscopy. 2005;21(6):652-658.

64. Monteiro GC, Ejnisman B, Andreoli CV, Pochini AC, Cohen M. Absorbable versus nonabsorbable sutures for the arthroscopic treatment of anterior shoulder instability in athletes: a prospective randomized study. Arthroscopy. 2008;24(6):697-703.

65. Moroder P, Blocher M, Auffarth A, et al. Clinical and computed tomography-radiologic outcome after bony glenoid augmentation in recurrent anterior shoulder instability without significant glenoid bone loss. J Shoulder Elbow Surg. 2014;23(3):420-426.

66. Moroder P, Hirzinger C, Lederer S, et al. Restoration of anterior glenoid bone defects in posttraumatic recurrent anterior shoulder instability using the J-bone graft shows anatomic graft remodeling. Am J Sports Med. 2012;40(7):1544-1550.

67. Moroder P, Hitzl W, Tauber M, Hoffelner T, Resch H, Auffarth A. Effect of anatomic bone grafting in post-traumatic recurrent anterior shoulder instability on glenoid morphology. J Shoulder Elbow Surg. 2013; 22(11):1522-1529.

68. Neyton L, Young A, Dawidziak B, et al. Surgical treatment of anterior instability in rugby union players: clinical and radiographic results of the Latarjet-Patte procedure with minimum 5-year follow-up. J Shoulder Elbow Surg. 2012;21(12):1721-1727.

69. Nocoletti S, Carrera EF, Ejnisman B, Netto NA. Bankart technique and Neer's capsuloplasty in the recurrent dislocation of the shoulder. Rev Bras Ortop. 1998;33:700-704.

70. Park MJ, Tjoumakaris FP, Garcia G, Patel A, Kelly JD. Arthroscopic remplissage with Bankart repair for the treatment of glenohumeral instability with Hill-Sachs defects. Arthroscopy. 2011;27(9): 1187-1194.

71. Petrera M, Patella V, Patella S, Theodoropoulos J. A meta-analysis of open versus arthroscopic Bankart repair using suture anchors. Knee Surg Sports Traumatol Arthrosc. 2010;18(12):1742-1747. 
72. Regan WD, Webster-Bogaert S, Hawkins RJ, Fowler PJ. Comparative functional analysis of the Bristow, Magnuson-Stack, and Putti-Platt procedures for recurrent dislocation of the shoulder. Am J Sports Med. 1989;17(1):42-48.

73. Russo R, Giudice G, Ciccarelli M, Vernaglia Lombardi L, Cautiero F. Anterior-inferior shoulder instability: treatment based on the Thal method. Chir Organi Mov. 2005;90(2):137-143.

74. Salomonsson B, Abbaszadegan H, Revay S, Lillkrona U. The Bankart repair versus the Putti-Platt procedure: a randomized study with WOSI score at 10-year follow-up in 62 patients. Acta Orthop. 2009; 80(3):351-356.

75. Selecky MT, Tibone JE, Yang BY, McMahon PJ, Lee TQ. Glenohumeral joint translation after arthroscopic thermal capsuloplasty of the rotator interval. J Shoulder Elbow Surg. 2003;12(2):139-143.

76. Shih JT, Lee HM, Tan CM. A modified Bristow procedure for recurrent anterior shoulder dislocation. Zhonghua Yi Xue Za Zhi (Taipei). 1995; 56(1):47-51.

77. Shively J, Johnson J. Results of modified Bristow procedure. Clin Orthop Relat Res. 1984;(187):150-153.

78. Steffen V, Hertel R. Rim reconstruction with autogenous iliac crest for anterior glenoid deficiency: forty-three instability cases followed for 519 years. J Shoulder Elbow Surg. 2013;22(4):550-559.

79. Sugimoto $Y$, Nakatsuchi $Y$, Saitoh S, Kutsuma T, Sugiura K. Treatment of recurrent anterior dislocation of the shoulder with Boytchev procedure one to seven-year follow-up results. Katakansetsu. 1987; 11(1):122-1228.

80. Wang L, Liu Y, Su X, Liu S. A meta-analysis of arthroscopic versus open repair for treatment of Bankart lesions in the shoulder. Med Sci Monit. 2015;21:3028-3035.

81. Willard DP. The Nicola operation for recurrent dislocation of the shoulder. Ann Surg. 1936;103(3):438-443.
82. Wintzell G, Haglund-Akerlind Y, Ekelund A, Sandström B, Hovelius L, Larsson $\mathrm{S}$. Arthroscopic lavage reduced the recurrence rate following primary anterior shoulder dislocation: a randomised multicentre study with 1-year follow-up. Knee Surg Sports Traumatol Arthrosc. 1999;7(3):192-196.

83. Wintzell G, Haglund-Akerlind Y, Nowak J, Larsson S. Arthroscopic lavage compared with nonoperative treatment for traumatic primary anterior shoulder dislocation: a 2-year follow-up of a prospective randomized study. J Shoulder Elbow Surg. 1999;8(5):399-402.

84. Wintzell G, Haglund-Akerlind Y, Tidermark J, Wredmark T, Eriksson E. A prospective controlled randomized study of arthroscopic lavage in acute primary anterior dislocation of the shoulder: one-year follow-up. Knee Surg Sports Traumatol Arthrosc. 1996;4(1):43-47.

85. Wintzell G, Hovelius L, Wikblad L, Saebö M, Larsson S. Arthroscopic lavage speeds reduction in effusion in the glenohumeral joint after primary anterior shoulder dislocation: a controlled randomized ultrasound study. Knee Surg Sports Traumatol Arthrosc. 2000;8(1): 56-60.

86. Wright JG, Einhorn TA, Heckman JD. Grades of recommendation. J Bone Joint Surg Am. 2005;87(9):1909-1910.

87. Wright JG, Swiontkowski MF, Heckman JD. Introducing levels of evidence to the journal. J Bone Joint Surg Am. 2003;85(1):1-3.

88. Yee AJ, Devane PA, Horne G. Surgical repair for recurrent anterior instability of the shoulder. Aust N Z J Surg. 1999;69(11):802-807.

89. Young DC, Rockwood CA. Complications of a failed Bristow procedure and their management. J Bone Joint Surg Am. 1991;73(7): 969-981.

90. Yuen MC, Tung WK. The use of the Spaso technique in a patient with bilateral dislocations of shoulder. Am J Emerg Med. 2001;19(1):64-66.

91. Yuen MC, Yap PG, Chan YT, Tung WK. An easy method to reduce anterior shoulder dislocation: the Spaso technique. Emerg Med J. 2001;18(5):370-372. 